\title{
XERIMBABO: EDUCANDO PARA UM FUTURO CONSCIENTE
}

Apresentação: Relato de Experiência

Fernanda Paulino da Silva ${ }^{1}$; Maria Lucivânia Diniz da Silva²; Brena Karisa Campos de Melo $^{3}$; Marta Maria Pinheiro ${ }^{4}$, Viviane da Silva Medeiros ${ }^{5}$

\section{Introdução}

Projetos que apresentem uma nova perspectiva sobre o ensino da educação ambiental e sanitária são relevantes para a formação dos estudantes desde as fases iniciais da educação. É um dos pilares da Universidade promover a extensão. A partir dessa necessidade o Projeto de Extensão Xerimbabo, da Universidade Federal do Rio Grande do Norte, tem sido desenvolvido em escolas municipais na cidade de Macaíba/RN, e tem como principal objetivo aprimorar, transmitir e acrescentar informações úteis na vida de crianças do ensino fundamental, na qual são discutidas temáticas como guarda responsável, importância da coleta de fezes de animais de estimação em locais públicos, medidas de higiene e as principais zoonoses que acometem animais e humanos no município. As crianças não são as únicas beneficiadas no projeto, a partir da sensibilização delas é possível levar o conhecimento adquirido em sala de aula para casa, e assim os familiares também entram nesse processo de aprendizagem, melhorando a qualidade de vida comunitária. A Educação Ambiental está comprometida com a ampliação da cidadania, da liberdade, da autonomia e da intervenção direta dos cidadãos na busca de soluções para convivência entre os seres humanos e outros seres, buscando a possibilidade de viver dignamente (REIGOTA, 2017). É um tema que deve ser discutido, ampliado e abordado na escola, buscando a melhoria do mundo em que vivemos, através da educação e da formação cidadã. Proposta desde 1988 na constituição brasileira onde preconiza que "Promover a Educação Ambiental (EA) em todos os níveis de ensino e a conscientização pública para a preservação do meio ambiente" (RODRIGUES et al, 2017). O projeto Xerimbabo, é um Projeto de extensão da UFRN, que atua desde 2012 em escolas da Zona Rural do município de Macaíba/RN permitindo que graduandos das ciências da saúde, tecnológicas e agrárias coloquem em prática a teoria aprendida em sala de aula aplicando da melhor maneira o conhecimento adquirido, através de apresentações e atividades interativas com alunos do ensino fundamental da rede municipal. Os alunos na faixa etária atendida de 13 a 16 anos, que participam do projeto demonstram interesse crescente na melhor forma de se criar animais, ter hábitos de higiene saudáveis e se proteger de enfermidades zoonóticas e crescerem em um ambiente saudável.

\section{Relato de Experiência}

O Xerimbabo é um projeto de extensão em educação para ambiente e saúde, tendo como objetivo discutir desde a guarda responsável, hábitos de higiene até os riscos de zoonoses com alunos do ensino fundamental de escolas públicas de Macaíba, cidade da área metropolitana de Natal, capital do RN. Uma das estratégias para o bem estar animal é controlar a população através de

\footnotetext{
${ }^{1}$ Discente de Zootecnia, UFRN, Fernandapaulino1996@live.com

${ }^{2}$ Discente de Zootecnia, UFRN, maria.lucivania1@live.com

${ }^{3}$ Discente de Zootecnia, UFRN, Brenakmelo@gmail.com

${ }^{4}$ Enfermeira da EAJ/UFRN, martakiss_@ hotmail.com

${ }^{5}$ Doutora em psicobiologia - Orientadora do projeto, UFRN, vivianemedeiros.eaj@gmail.com
} 
castrações a fins de diminuir o número de animais abandonados. O controle populacional de cães e gatos preocupa as autoridades sanitárias, especialmente com relação à disseminação de zoonoses (APARECIDA, Adolorata 2011). Uma estratégia de longo prazo é a educação das pessoas para o bem estar e para a proteção contra o risco potencial de animais de rua com relação a zoonoses, esta é a real importância assumida pelo Xerimbabo, trabalhar na conscientização de crianças e jovens para a guarda responsável dos seus animais de estimação, diminuindo assim o índice de animais abandonados e provável risco de transmissão de doenças entre animais e humanos.

Durante os 3 anos de atividade do Projeto, três escolas foram assistidas, com aproximadamente 60 alunos do ensino fundamental, 25 do terceiro ano fundamental e os demais do sétimo ano. 5 resumos científicos foram publicados, um artigo está em vias de submissão, 9 alunos de graduação em Zootecnia, Farmácia, Medicina Veterinária e Desenvolvimento de Sistemas, três alunos do ensino técnico e quatro professores.

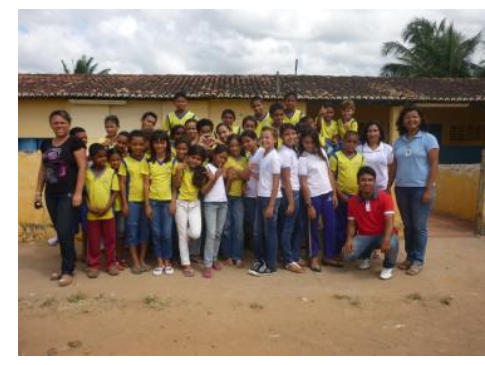

2012

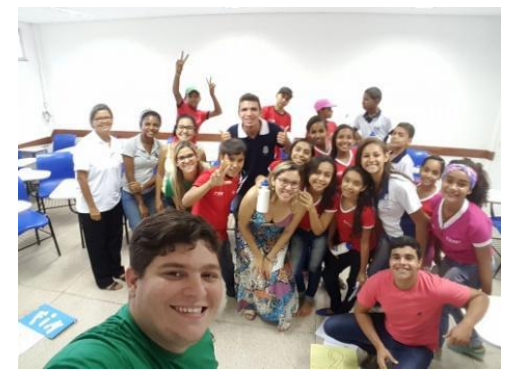

2016

Imagem 1e 2: Alunos e membros do projeto reunidos após dinâmica. Fonte: Própria

\section{Considerações}

As crianças de escola públicas municipais estão em famílias consideradas das classes mais pobres da sociedade, sobretudo as da zona rural. Os estudantes e profissionais participantes se dedicam para fazer desse projeto de extensão uma possibilidade de difusão do conhecimento levando uma possibilidade de vida mais saudável e de respeito, harmonia entre pessoas e animais. Cada criança que participa de uma ação leva para sua família informações que serão discutidas e aprendidas entre os familiares, talvez hábitos possam ser modificados a partir dessa ação. Cada apresentação sempre é pensada visando a melhor assimilação dos alunos através de diversas estratégias e recursos, focada sempre em metodologias ativas de ensino-aprendizagem como Teatro, filmes, projeções de slides, atividades lúdicas e dinâmicas. Espera-se que a cada ano uma nova turma seja assistida pelo projeto e ao final os alunos levem essa semente com eles.

\section{Referências}

APARECIDA, ADOLORATA. Caracterização da população de cães e gatos e avaliação do nível de conhecimento dos moradores sobre zoonoses e posse responsável de animais de estimação, em bairros do município de Jaboticabal/SP. Revista Ciência em Extensão, 2011.

REIGOTA, Marcos. O que é educação ambiental. Brasiliense, 2017.

RODRIGUES, Silva; NUNES, José Tomáz Ferreira; DA ROCHA, Josefa Eleusa. EDUCAÇÃO AMBIENTAL NA ESCOLA: UMA PROPOSTA PARA FAVORECER A APRENDIZAGEM, 2017. $\quad$ pesquisa $\quad$ realizada $\quad$ em $\quad 14 / 10 / 2017$ http://www.editorarealize.com.br/revistas/conedu/trabalhos/TRABALHO_EV045_MD1_SA10_ID6 217_07092015145930.pdf 